DOI: https://doi.org/10.47405/aswj.v6i1.162

\begin{tabular}{|c|}
\hline $\begin{array}{c}\text { Asian Social Work Journal (ASWJ) } \\
\text { JOORAALA WORK } \\
\text { (ASW) }\end{array}$ \\
Volume 6, Issue 1, January 2021 \\
\hline \\
\hline
\end{tabular}

\title{
A Review of Studies on Outcomes of Psychosocial Support Interventions: Nurturing Resilience in Looked-After Children
}

\author{
Amos Magut ${ }^{1}$ \\ ${ }^{1}$ Faculty of Education and Human Resource Development, Kisii University, Kenya \\ Correspondence: Amos Magut (magutamos14@gmail.com)
}

\begin{abstract}
Resilience is the quality of life in which a person is able to thrive against adverse internal and external conditions of life. This paper provides a framework for measuring resilience competency as a product of psychosocial support interventions. Resilience competency is one of the aims of psychological and social support given to persons who have undergone traumatic events or experiences. The researcher was biased towards the outcomes of psychosocial support given to looked-after children in care institutions. The paper is based on a review of literature on psychosocial support and resilience competency. The review focused on studies that have been published since the 1990s to date. The keywords used in the search for literature included psychosocial support, psychological support, social support, resiliency, resilience among children, looked-after children, psychosocial support and resilience. Based on the review of literature, the study found that researchers have identified many indicators of resiliency among looked-after children. Among these signs are: Having a sense of purpose in life, exhibiting optimism, emotional hardiness or emotional intelligence and active coping with life's challenges.
\end{abstract}

Keywords: outcomes, psychosocial support interventions, resiliency, looked-after children

\section{Introduction}

There are many children who live outside parental care. These are children who are forced by circumstances beyond them to fend for themselves. The first category of these children are those who are left without care for the majority of the day/night due to different reasons, including: Parents' illness, disability or alcoholism; parents being away on work for long hours or parents' imprisonment. Other categories include those without shelter and who live on the streets; those who work far away from home in farms and industries, and those who live in residential institutions (including those neglected by their parents for numerous reasons). There are also other children who have been placed in alternative care settings as a result of an administrative decision (by a welfare or protection body) or a judicial decision that withdrawal from parental care is in the child's best interests. Finally, there are those children who arrive in another country unaccompanied seeking asylum or immigration, or as victims of trafficking, and those separated by conflicts and disasters (SOS-Kinderdorf International, 2007; PEPFRAR, 2012).

Majority of these looked-after children have poor access to health care, education, food and safe shelter and are highly vulnerable to communicable infections, including HIV (Thembela, 2007). Moreover, their lack of adequate adult protection predisposes them to harmful environments plagued by factors like poverty, abuse, exploitation, and vulnerability to higher-risk activities that lead to HIV 
(Wawire, 2006). These factors affect many children in many parts of the world. This trend is more profound the sub-Saharan Africa, parts of Asia, South America and the West Indies where there are rising numbers of children who are leaving home to cater to their own needs (SOS-Kinderdorf International, 2007).

Most looked-after youth tend to exhibit fear in social contexts. A study by Saylor (1988) has found that a typical reaction to critical incidences encountered by such children include heightened levels of fear, anxiety, and sleep disturbances. This results in externalised behaviours such as aggression, fighting, bullying or impulsivity or internalised ones such as withdrawing from others, isolation, or failure to engage in a meaningful interaction with others causing a child to fail to develop effective social skills. Left untouched, these behavioural problems may drive children to engage in vices like stealing, breaking rules, truancy, abuse of drugs and sexual intercourse (Thomas et al., 2001). Children who engage in such vices cause stress to caregivers, find it hard to make friends and have difficulties understanding social situations. Moreover, they do poorly in class, feel worthless and blame others for their failures (Njenga, 2010). Therefore, once they enter into care, these children require greater levels of support and services in order to increase their protective factors and promote personal resilience to adversities.

Looked-after kids' experiences, once they are enrolled in a home, shape their health and can further compound the genesis and the type of challenges they face. Problems like abuse, loss of identity, among others, have the potential to further disrupt a child's growth and development. Interventions will guard against these children developing despair over life in care which can ultimately breed pessimism over their future (Centre on the Developing Child at Harvard University, 2017). This is a key consideration as research indicate that when young people are less optimistic about their future they are more likely to engage in risky behaviour (Conchas \& Clark, 2002). It is important, therefore, that these children are nurtured in a psychosocial environment that inculcates in them a strong sense of belonging, motivates and values their contribution and influences in the care environments (Vitoria Department of Human Services, 2008).

Child care environment can either be psychosocial or physical in nature. According to Regional Psychosocial Support Initiative (REPSSI) (2008), the word 'psychosocial' underlines the close relationship between cognitive and social effects of experiences as well as the continuous influence of the two on each other. Psychosocial support describes a continuum of care and support and aims at ensuring the well-being of children. The provision of psychosocial support services is targeted at enhancing the social, spiritual and emotional well-being of orphaned and separated children and may be preventative or curative in nature (Government of Kenya, 2013).

Ideally, psychosocial needs fall within three domains: Emotional well-being; Social well-being; and Skills and knowledge (ARC, 2009). Social well-being concerns the ability to build and maintain relationships, family and community networks, adhere to cultural traditions and engage in life tasks such as school or work. It involves maintaining good relationships with others, and the opposite of conduct disorder, delinquency, interpersonal violence and bullying. It can be concluded that social well-being is related to the improved ability of a looked-after youth to assume socially appropriate roles, which appears to be linked to a greater sense of the child being appreciated by people around them (ARC, 2009).

Emotional well-being encompasses an increased sense of security and confidence as indicated by reaching out and making friends, or at least participating in social activities (prosocial behaviour). Emotional well-being is key to looked-after children's successful adaptation to life, achievement of success in school, maintenance of positive relationships and good cognitive fitness (ARC, 2009). On the other hand, aspects in skills and knowledge domain of psychosocial provision are related to the acquisition of understanding that is linked to activities like festivals and sports. It also includes trainings related to issues like child rights, health information, safe behaviour and sessions on the qualities of friendly behaviour, conflict resolution, peace and forgiveness (ARC, 2009). In order for programmes in care homes to improve the psychosocial well-being of children, all the abovementioned psychosocial components need to be met (Racusin et al., 2005). As such, care homes 
should have in place intensive psychosocial provisions to be able to meet the heightened needs of looked-after children.

Psychosocial interventions in care homes (both residential and family types) ought to work through caregivers helping keep children in a therapeutic environment (ACCIK, 2016). This is achieved through the creation of positive, safe, healing relationships and experiences informed by a sound understanding of trauma. Moreover, it is achieved through understanding impact of damaged attachment and developmental needs on looked-after youths (McLean, Price-Robertson \& Robinson, 2011).

The above assertions are reinforced by a World Bank report of 2014 which that affirms that psychosocial interventions targeting children in alternative care must be aimed at addressing all their needs simultaneously. They ought to focus on children developing: Secure attachments with caregivers; meaningful peer relationships, friendships, and social ties; social competence; a feeling of belonging; a feeling of elevated self-worth and value, self-esteem and well-being; trust in others; access to opportunities for cognitive and spiritual development; physical and economic security, and, finally, hope, optimism and belief in the future. These proposals have been supported by a variety of authors and bodies (Ballew \& Mink, 1986; Ireland Children Acts Advisory Board, 2008; Woodside \& McClam, 1998; International Centre for Research and Innovation in Fostering, 2015). These works concur that in a care environment carers ought to: Provide meaningful participation of children in issues affecting them; listen and respond to children's problems; allow children to express their feelings and needs; help children to appreciate their history and identity; encourage children to set goals and reach their potential; ensure that children have positive, nurturing relationships and connections in their lives; facilitate family tracing and linkages; provide life skills for children and youth; and finally avail them with secure environments for sport. All these help to develop a resilient youth who can manoeuvre through the journey of life with confidence.

\section{The Concept of Resilience}

Studies have defined resilience variously. For instance, Ungar and Liebenberg (2011) posit that in the face of adversity, resilience is an individuals' ability to navigate their way to psychological, social, cultural, and physical resources as to sustain their well-being and to negotiate for these resources to be provided and experienced in culturally meaningful ways. On the other hand, Tan (2004) state that resilience is the quality that enables a child to find fulfilment in his or her live despite their underprivileged backgrounds, the tribulations or difficulty they may have undergone or the pressures they may go through.

According to Rutter (1999) and Schofield (2001) (as cited in Stein, 2005), resilience is about overcoming the odds, coping and recovery. He further posits that children who are best equipped to overcome adversities will have: strong social support networks; a committed mentor or person from outside the family; a range of extra-curricular activities that promote the learning of competencies and emotional maturity; the capacity to reframe adversities so that the beneficial as well as the damaging effects are recognised; the ability or chance to make a difference, for example by helping others through volunteering, or undertaking part-time work; and exposure to challenging situations that provide opportunities to develop both problem-solving abilities and emotional-coping skills. Children in care are vulnerable because of their historical and environmental circumstances and therefore require a greater level of support and services.

All children even those in care are born with the potential to be resilient, but resilience has to be developed, just like other skills and capacities (Tan, 2004). Resilience prepares children for hardships and suffering that they may face in the future - not only when they are young, but also when they are adults. Psychosocial services can support a child to build their resilience and overcome psychosocial suffering which in turn builds a foundation for a disposition of positivity in life. In addition, counselling can help a child to: Tell their story and make sense of difficult or negative experiences; understand, accept and live with strong feelings brought about by difficult Situations; make choices; 
DOI: https://doi.org/10.47405/aswj.v6i1.162

recognise their strengths; deal with fear and anxiety; develop a positive attitude to life, problem solve and how to move forward with their lives (Palmer, 2000).

\section{Personality Adjustment Competencies}

Personality refers to the characteristic pattern of thinking, feeling and acting (Mangal, 2007). It thus connotes the consistent and distinctive ways our ideas, feelings and actions are organized. Personality therefore refer to the totality or whole of the person. It means the enduring pattern expressed by the person in various situations is the hall mark of personality. On the other hand, adjustment is a psychological process by which an individual varies their behaviour to produce a more harmonious relationship between themselves and their environment. Adjustment gives individual ability and strength to bring desirable changes in the state of their environment. Additionally, it helps individuals to keep balance between needs and the capacity to meet the needs (Mangal, 2007).

Taken together, 'personality adjustment' denotes a quest to adapt to physical environment as well as to social demands. There are different forms of environment depending on where one is. The demands of these environments vary for example in care environment, children need to adapt to new routines and expectations which could be new to them - thus need to adjust their way of doing things (personality) in order to conform. This is personality adjustment. This action and reaction chain going on-between the individual and his environment go on and on whenever there is change of environment (Mishra \& Yadav, 2013). Then there are social pressure and demand of socialization. The process of adjustment becomes still more complicated when his/her way of interacting with one situation comes into conflict with the requirement of the other situation. One situation may give rise to pleasure while the other may give rise to anxiety. Mishra and Yadav posit that the resulting tension may cause disturbance in his psyche, produce uncomfortable physical symptom or may even lead to abnormal behaviour. For this not to happen an individual need to adjust.

The process of adjustment is complicated because a person's interaction with one demand may come in conflict with requirements of another. Conflicts can arise either because internal needs are in opposition, or because two external demands are incompatible with each other, or because an internal need opposes an external demand. Conflicts like this presents problems of adjustments. Satisfaction of one need as opposed to other needs may not provide full satisfaction. On the other hand, failure to gratify a strong need or to respond to a strong external demand may result in painful tensions which often lead to abnormalities. This is where personality competencies (adjustive processes) come in to mitigate things (Mangal, 2007).

Personality competencies help a person to modify an ingrained impulse, alter demands of the environment or generate defence mechanism to help one 'escape' painful experiences. Personality adjustment competencies emerge out of the need for a force to balance effect of human personality traits on one side and needs and demands of the environment of the on the other. Harmony is achieved if an individual is endowed with adequate competencies that can be used to manage such conflict. Such competencies include characteristics like self-esteem, resilience, social connectedness among others.

In a care home, personality adjustment is often interfered with by a history of trauma and loss. Exposure to ongoing and repetitive traumatic experiences may have caused the children to have profound and reverberating effects, which impact developing neurobiological structures, adaptive and coping strategies, psychological symptom patterns, and even psychopathology (Kluft, Bloom \& Kinzie, 2000). This may then manifest as nervous disorders, psychotic behaviour and even educational difficulties. There is an urgent need for these children to be provided psychosocial care in order to build their personality adjustment competencies. According to PEPFAR (2012), this may be provided through everyday interpersonal interactions that occur in caring relationships in care homes and schools. Such care and support include the love and protection that children receive in living environments, as well as interventions that help children cope. Such interventions enable children to 
form a sense of self-worth and belonging and are essential to learning, developing life skills, participating in society, and having faith in the future.

Young people in care face a variety of challenges which ideally require timely prevention and intervention strategies from caretakers, counsellors, administrators and relevant government departments. Problems like abuse, loss of identity, among others have potential to disrupt a child's growth and development. Interventions will guard against these children developing despair over life in care which can ultimately breed pessimism over their future. This is important as research indicates that when young people are less optimistic about their futures they are more likely to engage in risky behaviour (Conchas \& Clark, 2002). Consequently, programmes geared towards building personality competences of looked-after children ought to be in place and running. This study will focus on one competency, namely resilience. This competency is key in facilitating a child's: interaction with the environment, participation in community endeavours and building quality relationships with peers and adults (Association of Charitable Children Institutions in Kenya [ACCIK], 2016). It is vital therefore that care homes through guidance and counselling service provide for these competency as it is apparently key contributor of positive mental health and development among the disadvantaged children.

\section{Results and Discussion}

\section{Psychosocial Support Intervention and Resilience Competency}

Authors have defined resilience variously. For instance, Ungar and Liebenberg (2011) posit that in the face of adversity, resilience is an individuals' ability to navigate their way to psychological, social, cultural, and physical resources as to sustain their well-being and to negotiate for these resources to be provided and experienced in culturally meaningful ways. On the other hand, Tan (2004) state that resilience is the quality that enables a child to find fulfilment in his or her live despite their underprivileged backgrounds, the tribulations or difficulty they may have undergone or the pressures they may go through.

According to Rutter (1999) and Schofield (2001) (as cited in Stein, 2005), resilience is about overcoming the odds, coping and recovery. He further posits that children who are best equipped to overcome adversities will have: strong social support networks; a committed mentor or person from outside the family; a range of extra-curricular activities that promote the learning of competencies and emotional maturity; the capacity to reframe adversities so that the beneficial as well as the damaging effects are recognised; the ability or chance to make a difference, for example by helping others through volunteering, or undertaking part-time work; and exposure to challenging situations that provide opportunities to develop both problem-solving abilities and emotional-coping skills. Children in care are vulnerable because of their historical and environmental circumstances and therefore require a greater level of support and services.

All children even those in care are born with the potential to be resilient, but resilience has to be developed, just like other skills and capacities (Tan, 2004). Resilience prepares children for hardships and suffering that they may face in the future - not only when they are young, but also when they are adults. Psychosocial services can support a child to build their resilience and overcome psychosocial suffering which in turn builds a foundation for a disposition of positivity in life. In addition, counselling can help a child to: Tell their story and make sense of difficult or negative experiences; understand, accept and live with strong feelings brought about by difficult Situations; make choices; recognise their strengths; deal with fear and anxiety; develop a positive attitude to life, problem solve and how to move forward with their lives (Palmer, 2000).

\section{Indices of Resiliency}

The study undertook an in-depth review of studies on the indicators of resilience among looked-after persons. The assumption of the researcher was that individual resilience might be achieved through 
taking survivors of trauma through therapy. Moreover, it is an established fact that others naturally recover from effects of traumatic events over time and move on without having severe, long-lasting mental health issues. This is attributed to individuals possessing certain resilience factors that increase resilience after traumatic events. Among the key scholars reviewed under this section is Helmreich et al. (2017) who provided the main themes under which the literature reviewed was categorised. According to Helmreich et al. (2017), such psychosocial resilience factors include meaning or purpose in life, emotional hardiness, optimism and active coping.

\section{Purpose in Life}

Having purpose in life is a key aspect in development and maintenance of resilience. This is so because it motivates individuals to reframe stressful situations in order to deal with them more productively, thereby facilitating recovery from stress and trauma. It does this by providing a buffer from negative events, promoting reappraisal and motivated coping processes, decreasing brooding and ruminative thinking styles, supporting faster and better recovery, and thus increasing resiliency (Helmreich et al., 2017). A meta-analysis by Cotton et al. (2009) has revealed that having a purpose in life contributes to a number of positive outcomes. It contributes to optimal human development in a variety of ways; contributes to rejuvenation of developmental asset; is an important component of human flourishing; is associated with greater levels of happiness and resiliency; makes those who have it psychologically healthier; enables people to endure life's hardships; helps young people successfully navigate and resolve their identity 'crises', and correlates with greater involvement in social activities. The looked-after youths need to be trained to have a meaning about life, during their stay in care. This may entail introducing to them the benefits of purpose in life; supporting them in identifying important sources of meaning (e.g. social relationships, school and college) as well as in setting priorities and guiding values for their life (Helmreich et al., 2017). Specific teaching points for training on acquisition of purpose in life include: how to live one day at a time and not to think too much about the future; having a good sense of what it is that one is trying to accomplish in life; setting achievable goals; carrying through with plans; and being strategic on how one handles issues (Seifert, 2005).

\section{Optimism}

Optimism in humans reflect a sense of physical security, a sense of a safety net now and in the future, and self-efficacy in being able to succeed in life. It is an established fact that when youth are less optimistic about their futures, they are more likely to engage in risky behaviour (Conchas \& Clark, 2002). On the contrary, optimistic youths have important goals for their life. Additionally, they believe: they have what it takes to succeed in life; that somebody will take care of them when they are old; that their future will work out; and that if they work hard enough, they can accomplish anything (Narvaez, 2006).

From the foregoing it is apparent that individuals, especially the youth, need to be assisted to have higher levels of optimism in order not to engage in risky behaviour. The looked-after youth in particular need to be helped to fully develop this aspect of resiliency. Helmreich et al. (2017) proposes that they are taught to adapt a more positive attributional style for stressful and pleasant events and also encouraged to gain a brighter outlook for the future by enhancing their attention for and the discovery of positive aspects in their lives. This way they acquire a sense of direction over their future as they have a feeling of having mastered their personal and environmental spaces.

\section{Emotional Hardiness}

To be 'hardy' means to be strong and tolerant of stressful situations like life demands, abuse and negative influences. Hardiness is conceptualized as the courage that protects against such effects of denial and avoidance of life's stressors (Tetsuhiro, 2016). In addition, hardier persons are seen to take control of their lives, believe that commitment to goals will result in positive outcomes, and perceive daily stressors as challenges (Gwen van Servellen et al., 2010). In a ground-breaking work in 1979 on the concept of hardiness, Suzanne Kobasa posits that hardiness comprises of three beliefs that makes individuals more resilient to psychological distress and physical illness in the face of stress. The first is 
commitment. She avers that hardy individuals are committed to their work and families. They believe that what they are doing is important. Moreover, they find meaning in their activities even when faced with significant adversity precisely because they are committed to finding that meaning. In addition, they consistently take an active, problem-solving approach to life (Mills \& Dombeck, 2005).

Secondly, emotionally hardy people tend to accept challenges and tend to work to overcome and master them. This imply they are able to perceive themselves as having control over their outcomes instead of feeling powerless to influence events. Moreover, they seize upon opportunities for exploring new options rather than become depressed and demoralized over a lost course (Mills \& Dombeck, 2005). Thirdly, hardy people view stress as a test that they can potentially surmount if only they can comprehend it properly. Their tendency of looking at stress as a challenge to be overcome motivates them to deal with the causes of their stress in constructive ways. They therefore view the demands of the situation as a challenge or opportunity instead of a threat. As a result, the situation is seen as less stressful and provided an opportunity to excel (Mills \& Dombeck, 2005).

Hardiness training is ideally embedded in psychosocial support services in care homes. It entails using a set of techniques to try and shape youths to become psychologically 'hardy. Owing to challenges they have encountered from their original backgrounds, these youths may often exhibit behaviours that are associated with lack of hardiness if they are not supported in good time. Such behaviours may be internalised ones like low self-esteem, giving up easily on things, isolation and poor social connectedness.

Support interventions ought to help build a looked-after youths' resilience through strengthening their hardiness. First, they need support to help them focus on the physiological symptoms associated with stressful situations so as to help them identify sources of stress. The therapist would then be able to help them acquire new skills and strategies for coping with stress. Secondly, the interventions need to facilitate a reconstruction of stressful situations where the youths are encouraged to think about recent stressful situations, and in particular how they might have turned out better and how they might have turned out worse. Thirdly, interventions ought to help turn stressors into challenges and lead to a greater sense of personal control. In this way emotional hardiness will be established which in turn contributes to resilience and overall mental health of the youth (Helmreich et al., 2017).

\section{Active Coping}

Many looked-after youth do not have the life experiences or coping skills that would assist them in responding to the traumatic encounters in their lives. As a consequence, they need a well-planned, professionally staffed and supervised environment in residential care to facilitate the growth of active coping mechanism. Active coping entails an individual employing strategies that involve enlisting social support, managing emotional responses to stress, and gathering information and taking direct action. All this enable them to guard against or offset stressful events before their full implications may be felt. Such abilities to cope actively and proactively with respect to health may minimize adverse physiological effects of traumatic past (Shelley et al., 2000).

There is need for caregivers to boost capacities of youth under their care to cope better with life challenges. This is a key hallmark in resiliency research which indicates that resilient individuals have psychosocial resources to cope through adverse environments like ones that encourage maladaptive avoidant behaviours in and out of school (Sherman, 1994). To guard against such eventuality, Helmreich et al. (2017) propose that vulnerable individuals be trained on problem-solving and be familiarized with the use of active coping strategies in stressful situations. Such strategies include: Pointing out the amusing aspects of the problem at hand, or "positive reframing," in order to help deal with small let-downs; finding emotional support from caregivers or friends in order to maintain emotional health during a stressful period; locating the source of a problem and determine solutions; engaging in relaxing activities, or practicing calming techniques, in order to help to manage stress and improve overall coping; engaging in regular exercise, such as running, or team sports and other techniques of relaxation as a way to handle the stress of given situation; and finally adjusting expectations in order to prepare for the stress associated with any given change or event. It is thus 
DOI: https://doi.org/10.47405/aswj.v6i1.162

paramount that these strategies be incorporated into psychosocial support interventions provided in care homes as they have potential to nature resiliency.

\section{Conclusion and Recommendations}

From the reviewed studies, resilience is generally conceptualised as the quality that enables a child to find fulfilment in their life despite their underprivileged backgrounds, the tribulations or difficulties they may have undergone or the pressures they may suffered. The study identified four indicators of resilience that care givers should look out for when intervening in the lives of the looked-after youths, namely: exhibiting a purpose in life, a constant show of optimism despite the changing circumstances of life, emotional hardiness, and active coping with challenges.

It is recommended that care institutions should develop a policy manual for measuring resiliency based on the evidence provided by research. Such evidence-based practice will help these institutions to provide quality and needs-based psychosocial interventions for looked-after children. Additionally, since this paper was based on a review of literature, empirical studies should be conducted in care institutions to improve the quality and currency of knowledge in the field of psychotherapy.

\section{References}

Action for Rights of Children (2009). Psychosocial Support. Retrieved from http://www.arconline.org Association of Charitable Children Institutions of Kenya (2016). Manual for Charitable Children's Institutions in Kenya. Nairobi: ACCIK.

Ballew, J. R., \& Mink, G. (1986). Case Management in the Human Services. Charles C. Thomas Publisher, Limited.

Centre on the Developing Child at Harvard University (2017). Resilience. Retrieved from https://developingchild.harvard.edu/science/key-concepts/resilience/

Conchas, G. Q., \& Clark, P. A. (2002). Career Academies and Urban Minority Schooling: Forging Optimism despite Limited Opportunity. Journal of Education for Students Placed at Risk, 7(3), 287-311.

Cotton, B., Kendall, H., Patrick, L., Lapsley, D. K., Talib, T. L., \& Finch, H. (2009). Purpose, hope, and life satisfaction in three age groups. The Journal of Positive Psychology, 4(6), 500-510.

Gwen van Servellen, M. T., \& Leake, B. (2010). Personality Hardiness, Work-related Stress, and Health in Hospital Nurses. Hospital Topics, 72(2), 34-39.

Helmreich, I., Kunzler, A., Chmitorz, A., König, J., Binder, H., Wessa, M., \& Lieb, K. (2017). Psychological Interventions for Resilience Enhancement in Adults. Cochrane Database of Systematic Reviews, Issue 2. Art. No.: CD012527. DOI: 10.1002/14651858.CD012527.

International Centre for Research and Innovation in Fostering (2015).Promoting best outcomes for children and providing best support for carers: A review of selected literature for Foster Care Associates, International Centre for Research and Innovation in Fostering.

Ireland Children Acts Advisory Board (2009). Best Practice Guidelines for the Use and Implementation of Therapeutic Interventions for Children and Young People in Out of Home Care. Belfast: Ireland Children Acts Advisory Board.

Kluft, R., Bloom, S., \& Kinzie, J. (2000). Treating the Traumatized Patient and Victims of Violence. In C. C. Bell, (Ed.). Psychiatric Aspects of Violence: Issues in Prevention and Treatment (pp. 79-102). New Directions in Mental Health Services 86, Summer.

Mangal, S. K. (2007).Essentials of Educational Psychology. New Delhi: PHI Learning.

McLean, S., Price-Robertson, R., \& Robinson, E. (2011). Therapeutic Residential Care in Australia. Taking stock and moving forward. National Child Protection Clearinghouse Issues Paper, 35. Melbourne: Australian Institute of Family Studies.

Mills, H., \& Dombeck, M. (2005). Resilience: Hardiness. Retrieved March 2, 2018 from https://www.mentalhelp.net/articles/resilience-hardiness/ 
DOI: https://doi.org/10.47405/aswj.v6i1.162

Mishra, K., \& Yadav, B. (2013). Job Anxiety and Personality Adjustment of Secondary School Teachers in Relation of Gender and Types of Teacher. Educational Research International, $1(1)$.

Narvaes, D. (2006). Guide for using the Positivity Scale. Centre for Ethical Education, University of Notre Dame.

Njenga, F. (2010). What is wrong with this Child? Nairobi: Oxford University Press.

PEPFAR (2012). Orphans and Vulnerable Children (OVC) Programming. PEPFAR.

Racusin, R., Maerlender, A. C., Sengupta, A., Isquith, P. K., \& Straus, M. B. (2005). Psychosocial treatment of children in foster care: A review. Community Mental Health Journal, 41(2), 199221.

Regional Psychosocial Support Initiative (REPSSI) (2008). Mainstreaming Psychosocial Care and Support - A Manual for Facilitators. REPSSI.

Saylor, C. F. (1988). Children and Disasters. New York, NY: Plenum Press.

Seifert, T. (2005). Assessment of the Ryff Scales of Psychological Well-Being. Retrieved March 2, 2018 from: http://www.wabashnationalstudy.org/wns/ryff.html

Shelley, E., Margaret, E., Julienne, B., Tara, L., \& Reed, G. (2000). Psychological Resources, Positive Illusions, and Health American Psychologist, 55(I), 99-109.

Sherman, T. (1994). John Henryism and the Health of African-Americans. Culture, Medicine and Psychiatry, 18, 163-182.

SOS-Kinderdorf International (2007). Children without parental care or at risk of losing it. Position Paper of SOS-Kinderdorf International. Retrieved March 10, 2018 from http://www.europarl.europa.eu/hearings/20070417/libe/sos_children_en.pdf

Tetsuhiro, Y., Moshier, S. J., \& Otto, M. W. (2016). No site unseen: Predicting the failure to control problematic internet use among young adults. Cognitive Behaviour Therapy, 45(6), 496-500.

Government of Kenya (2013). The National Standards for Best Practices in Charitable Children's Institutions. Nairobi: Government Printers.

Thembela, L. (2007). An Evaluation Of A Psychosocial Support Intervention For Vulnerable Children (Unpublished $\mathrm{PhD}$ thesis). University of Zululand.

Thomas, J., \& Guskin, K. (2001). Disruptive behaviour in young children: What does it mean? Journal of the American Academy of Child \& Adolescent Psychiatry, 40, 44-51.

Ungar, M., \& Liebenberg, L. (2011). Assessing Resilience Across Cultures Using Mixed Methods: Construction of the Child and Youth Resilience Measure. Journal of Mixed Methods, 5(2), 126149.

Victorian Health Promotion Foundation (2015). Current theories relating to resilience and young people: a literature review. Melbourne: Victorian Health Promotion Foundation.

Wairire, G. G. (2006). Psychosocial care for orphaned and vulnerable children in Kenya. In International Symposium for Practitioners and Policy Specialists on addressing the needs of Young Carers. Nairobi: Safari Park Hotel.

Woodside, M., \& McClam, T. (1998). Generalist Case Management: A method of Human Service Delivery. Pacific Grove: Brooks/Cole Publishing Company. 